\title{
UNVEILING THE AFTERMATH OF EDUCATION-JOB MISMATCH AMONG UIC BUSINESS ADMINISTRATION GRADUATES
}

\author{
Erica Lauron \\ Darwin Duran \\ Joan Ordaneza \\ Ronald Langam \\ Elizabeth Noveno \\ Irina Nanolan \\ Cheska Obligado \\ Nhicole Mangarin \\ Earl Castillo
}

March 2019

Correspondence:

\author{
Earl Castillo \\ Team Leader \\ University of Immaculate Conception \\ Annex Campus \\ Bonifacio St., Davao City 8000 \\ Davao del Sur, Philippines \\ (082) 2271573 \\ (082) 2273794
}




\begin{abstract}
This study explores the different perspectives of UIC graduates regarding education-job mismatch and interpreted it to create a possible model of its perceived causes and impacts, according to the participants themselves. The participants were two (2) female and one (1) male graduate of Business Administration who is currently experiencing education-job mismatch. The researchers' implied semi-structured interviews and thematic analysis to gather and interpret data. They were able to form 12 themes that are divided into 4 categories that successfully answered the research questions of this study. Results show that some of the perceived causes of education-job mismatch is weak economy and inadequate job opportunities, field of study, and theory and practice misalignment. Thus, the findings of this study suggest that education-job mismatch itself is caused by a weak economy which also causes a weak economy.

Keywords: Education-Job Mismatch, Business Administration, semi-structured interviews, thematic analysis.
\end{abstract}




\section{INTRODUCTION}

\section{BACKGROUND OF THE STUDY}

Education-Job Mismatch or Educational Mismatch refers to the incoherence of the required educational level for a specific job (Betti, Neri \& D’Agostino, 2010). Its two types are overeducation which means a worker has excess education for his/her work, and on the other hand, undereducation which refers to a scenario wherein a worker has less education for his/her work (Rahona-López and PérezEsparrells, 2013). It was a recognized issue across the world causing poverty and unemployment. Several studies have been made and developed since its first recognition in Canada and the United States during the early 1970s. The results show that a percentage of the employed population is experiencing educational mismatch (Somers, Groot, Cabus and Maassenvandenbrink, 2016). The studies of Dalton et al. (2000), Chevalier and Lindley (2006), Dalton and Silles (2008), altogether forms the same claim which explained the impacts of overeducation to graduates and the labor market in the United Kingdom. Based on all the data presented from various and several researchers, it can be inferred that educational mismatch is a serious problem worldwide, which affects both the labor market and the graduates themselves.

The Philippines is also experiencing education-job mismatch and has been a common phenomenon in the field of employment since then. Colina (2014) stated in his article which talks about the Educational mismatch that happened and is still happening now. He had stated that according to the Department of labor and Employment, when the skills required for the job does not fit with the what the job seeker has, it is considered as job mismatch, saying it is a crucial problem and it does not happen only in the Philippines. It brings a massive impact on the unemployment rate of a country. The labor department discusses this with the sector of education namely DepEd, CHEd, and TESDA, to update their curricula that will enhance the skills of the students to meet the requirements of the industries. 
According to Uy (2015), a labor group called "MANILA" has warned the public that about 1.2 million college and vocation graduates will have difficulties in finding a job due to the increasing rate of educational mismatch in the country and overseas. TUCP-Nagkaisa or The Trade Union Congress of the PhilippinesNagkaisa, states the records released by the Department of Labor and Employment showing out of the 4.23 million domestic and international job vacancies that are offered in all the job fairs in the span of 2 years, from 2014 to 2015, approximately 391,000 was hired on the spot, out of the 1.29 million applicants. TUCP-Nagkaisa quoted this as a "crisis" which continues to grow" (Tanjusay, 2015 on Uy, 2015, p. 1).

The Educational mismatch is also present here in Davao City. Actually, on May 1 to 2, 2018 at the Gaisano Mall of Davao, a job and business fair has been conducted. Job mismatch have been blamed for a small number of hires during the job fair. A data was released by the Department of Labor and Employment Region XI (2018). It shows that only 238 applicants were hired out of the 5174 jobseekers. The president of the Davao City Chamber of Commerce and the Industry, Arturo Milan (2018) argued that the government should find solutions for the said problem to address the demand for a qualified workforce. He stated that there is something that does not fit with the requirements of a job. That is why the government should develop the skills of the workers and soon to be workers. He also added that the mismatch is getting worse because the specific job that some unemployed individuals is looking for is already unavailable. Based on the data released by the Department of Labor and Employment, it can be proven that a solution is very important as the rate might increase even more if it is not solved. This problem prompted the researchers to study the topic, as it might be the solution towards Educational Mismatch.

Several studies were conducted that is related with the study of the researchers. One of which is the study of, Rahona-Lopez and Perez-Esparells (2013). They have found out that graduates in Spain have a lower chance of being overeducated on their first job. The results of their study show that, that $32.3 \%$ of 
graduates are overeducated on their first job, while $18.7 \%$ are undereducated. It means that most of the graduates tend to have jobs that require lesser skills than that of they have. Because of this, these individuals are more likely not able to maximize their potential, skills, and profit in working. They have also found out that undereducation is common to men than in women. Also, they have stated that only $20 \%$ of individuals both on vocational training and secondary education has jobs that fit their educational attainment and that overeducation has covered over $55 \%$ from it. The highest rate of undereducation are from forced education having $31.8 \%$, and $10 \%$ of it comes from vocational training. The study of Rahona-Lopez and Perez-Esparells (2013) does not just produce numbers but evident and observable occurrences of the society particularly the labor market field.

The uniqueness of this study comes with its aim. Other studies may have focused on the effects and causes of educational mismatch, but this study deals more with the perspective of the people, particularly UIC Graduates in the field of business administration, about it. The research aims to know the different perspective of UIC Graduates in the field of business administration about Education-Job Mismatch. The researchers expect that the data that they can gather can contribute to the formulation of a solution to educational mismatch.

The researchers have several purposes in making this study such as to give a solution to the problem of Educational Mismatch while having further exploration as to why the rate of Educational Mismatch is still increasing. Also, this study will contribute to CHEd, TESDA, DepEd and other organizations to realize the urgent need to address the problem of Educational Mismatch. Finding possible solutions to this problem will help not just the UIC graduates in the field of business administration but also those who experience educational mismatch.

This study focuses on exploring the different perspective of UIC graduates in the field of business administration towards Educational Mismatch. Specifically, it attempts to answer the following question:

- How does UIC graduates in the field of business administration face the problem of education-job mismatch? 


\section{THEORETICAL LENS}

This phenomenological study is based and inspired by several theories that are still under investigation such as, Matching Theory of Educational Mismatch, Job-Fit Theory, Endogenous Theory of Professionalization, New Measure of Skills Mismatch Theory and Human Capital Theory.

The first theory that is related to this study is the Matching Theory of Educational Mismatch by Ordine and Rose (2017). It stated that individual mismatch does not refer that a particular group of graduates exceeds what is necessarily required for a job. Individual Mismatch can be associated with either under and over-education. Laws regarding having access to higher education may have different effects on individual mismatch, depending on the situation. There are cases where promotion of participating in higher education may help in reducing the incidence of mismatch. To give a deeper connection to our study, this theory states of one possible solution in reducing this incidence, promotion of participating in higher education. It is because of the fact that most companies are hiring college graduates. Even if your course is not related to the work you are applying, your chances of getting hired is higher compared to a person that has not graduated. There are also cases wherein undergraduates being undereducated are forced to apply for jobs that they are not familiar about, or they have not studied well for them to earn a living, and this is also one of the causes of Educational Mismatch.

The next theory is from Kim and Choi (2018) all about Job-Fit Theory. JobFit refers to the extent wherein the job characteristics performed by an individual worker and the knowledge, skills, and capacities required for job performance correspond or are appropriate. According to them, the more the quality of the worker fits into the workplace, the higher the performance of an individual in their field of work. Job-fit Theory also focuses on the unlikeness between personal characteristics and the job's characteristics. Through this theory, the researchers can identify whether a worker is fit for its job or job characteristics. 
Another theory also is the Endogenous Theory of Professionalization. Made by Ghaffarzadegan and Larson (2017), this theory talks about the endogenous growth of Education-Job Mismatch. They created a pipeline which shows the connection between Education and the Workforce. According to them, the numbers of educated people are dramatically increasing with relatively short-term changes in the job market. The effects of this theory are degree inflation, magnified pressures on those with lower degrees, underemployment and job market mismatch and inefficiency. This theory says that the large growth of educated people cannot be all accommodated by the job market leaving others to experience the side effects. This issue is still happening today, and no said solutions are proven to be effective. Because of this, the researchers will now be able to consider a partial cause of educational mismatch, and this will help the researchers to find a solution if the roots of the problem are related with this theory.

The next theory is the New Measure of Skills Mismatch Theory by Pellizari and Finchen (2013). It states that the cause of skill mismatch is the lack of knowledge of the people for the jobs that are in demand. Furthermore, this might be because, in demand jobs are paying higher, that is why most of the people are choosing to apply for that specific job even if they do not have proper education towards it. It adds up to the increasing probable causes of educational mismatch that will be put into consideration by the researchers. Just like the other one, this theory will help the researchers in having a solution to address the problem caused by what is presented in this theory which is lack of knowledge of the people for the jobs that are in demand.

The last theory that is related to the researchers' topic is the Human Capital Theory by Prisca (2016). This theory focuses on the Education-Job Mismatch among university graduates in Cameroon. According to him, Education-Job Mismatch is very unnecessary, and the government should provide a solution to that problem. This theory views educational mismatch as a temporary phenomenon. Individuals who are still experiencing education-job mismatch, will later on, find a job that suits him/her very well based on his/her knowledge, skills 
and capacities as an individual. This theory relates to the researchers' study in a way that it helps the researchers' in formulating a solution as it suggests educational mismatch is only a temporary phenomenon. This means that if this theory will be proven reasonable and factual based on evidences, the researchers' will now have an easier way of making a solution because it is only temporary. If it will not be proven true, this theory will still help the researchers' in a way that they may now be able to search for more ideas and solutions towards this problem.

Therefore, these theories will be considered by the researchers in making this study, as this might significantly affect the results.

\section{REVIEW OF RELATED LITERATURE}

This chapter tackles the related literature of the study. It presents several studies for better understanding of the researchers' study.

\section{Causes of Mismatch}

The book, Horizontal Mismatch between Employment and the Field of Education: Evidence from a Systematic Literature Review by Somers et al., (2016), provides a systematic review of the increasing literature regarding the poor match between the workers' degree in his/her field and his/her work requirements also called as horizontal mismatch. They identified the different definitions used in the literature and found out that each measure of mismatch provides a significantly different incidence rate. They discussed its validity and have concluded that a more uniform description of horizontal mismatch in needed. According to them, its chances of occurring is among the things that are determined by the extent where workers' capacity involves general skills that opposes the work's specific skills, and it appears to happen more often to older workers. In comparison with the wellmatched employees, mismatched employees that generally incur a wage penalty, are less satisfied with their jobs and has more chances of regretting their study program. Their occurring findings offer guidance in order to avoid or at least reduce this incidence and to have as well a roadmap for future studies. 
However, the book The Sociology of Educational Mismatch by Aleksander Kucel does not oppose the previous study but raises another cause for educational mismatch. In this book, the theoretical relationships between core research lines of sociology are being studied. Under this are, intergenerational mobility, class structure and cultural capital, together with educational mismatch. The conclusions of a theory namely, Rational Action Theory - an economic principle that assumes that individuals make decisions that will have them the highest amount of personal utility, benefit, satisfaction, and depending also in their personal interest/s. - by Gary Becker is being considered by Kucel (2011) while analyzing the educational mismatch and individual's rational choices in their educational careers. Through this, Kucel and his co-researchers came to conclusions where the influences between education between educational mismatches and social classes are bidirectional and it is possible to create fairly clear theoretical links between class of origins and the chances of being educationally mismatched.

\section{Kinds of Educational Mismatch}

An article released by ISRN Education which is authored by Marta RohonaLopez and Carmen Perez-Esparrells entitled Educational Attainment and Educational Mismatch in the First Employment in Spain tells a whole new story. It states that, there is a high demand of work in the last decade of the 20th century for higher education in Spain. Overeducation is a common phenomenon, but in Spain graduates have a lower chance of being overeducated on their first job. Jobmismatch was first discovered on the year 1970s, the first countries to have a study about it were Canada and United States. Since then some researchers have break down the effect among different developed countries. There have been two results found in this study, first the education attained by an individual, second is the level

of studies required for a specific job. There are two kinds of educational mismatch: overeducation, happens when an individual is over-educated on his/her work. Undereducation, which occurs when a person lacks education to do a certain job. The outcome of the study shows that $32.3 \%$ of individuals are overeducated on their first job, while $18.7 \%$ are undereducated. In order for the study to be 
explained, it focuses on the education system of Spain over decades such as, the increase of teenage studies, and their difficulties in getting the right job. Overeducation is common among women and uncommon to men; While undereducation is more common for men, than in women. Only $20 \%$ of people on vocational training and on secondary education have jobs that matches their educational attainment. Over-education has covered over 55\% of people from vocational training and secondary education. The highest percentage of undereducated workers are from compulsory education with $31.8 \%$ but $10 \%$ of this are from vocational training. Aside from that the study shows that far from being a hidden fact, educational mismatch (more importantly overeducation) does not only affect individuals that are university graduates, but also affects people that have low level of education. The reason behind this is that, there is a chance in which women are being discriminated in the workplace, that could lead to difficulties in searching for a suitable job. It is anticipated that educational determinants can change the outcome, and there is a strong relation between the match of employment and the level of education among the workers. In account to family members, the results show that an individual having a father with secondary or university education, demotes the probability of being an overeducated worker. While on the other hand, its opposing result is on the worker having a father that is unskilled and unemployed. In other words, the family networks, connections, education and labor situation of the father could raise the quality of the worker's first employment. The longer the duration of an individual being unemployed is the semblance of having low human capital, and it reduces the rate of having workers find their own appropriate job. University education are often criticized for the absence of proficiency adjustment to the requirements of jobs in the labor market. In Spain overeducation is an expansive phenomenon on graduates' first stages of careers. And it is fact a very big struggle for graduates for many years already. Overeducation is common for individuals who have low level of studies. Educational mismatch aside for being a frequent phenomenon, it deserves to put into account by the Spanish educational and labour policies. 


\section{Effects of Overeducation}

This is supported by the study of Velciu (2017) entitled Job Mismatch Effects on Work Productivity. Individuals indeed are having a hard time finding their very own appropriate job. For the company, it is so hard to find an individual who is fit for a specific work. The success of a company is on the hands of the employees, because they are the one who is working. So, if their skills do not complement the job they are working in, it will affect the productivity of the company. And also, over qualified individuals are good just by the fact that they have excess skills for the job, but there are some who'll find another job that can challenge their skills and as well as get high compensations. They tend to look for other jobs, and that causes a company to lose employees. So, Job Mismatch can affect not only the employees but also the company or business and its future. So before hiring an employee, one should look at his/her skills and educational attainment, to make sure that he/she is the best or the most suitable applicant for the position.

An article written by Severine Degallaix (2016) entitled Over Qualification and Job Satisfaction: The Study, backs up the claims of Velciu (2017). It states that, over qualified workers are less satisfied and less productive in their work. Based on the data released by Program for International Assessment of Adult Competencies (PIAAC) and the statements made by several employees about their degree level in comparison to the position or job that they are currently in, Statistics Canada has published a study showing the relationship between overqualification and job satisfaction. Results show that, $12 \%$ of Canadians that are aged between 25 to 64 obtaining a university degree said that they held and overqualified job in 2012, a position that could have been possible to perform with a high school diploma. The proportion varies with a specific criterion, increasing to $27 \%$, for example, for employees that are born abroad, compared to $8 \%$ for those who are born in Canada. Among all university graduates, about $19 \%$ said that they had to finish college education in order for them to accomplish their studies, and $69 \%$ said that their level of qualification was just appropriate and enough since

their job required university graduates. Out of all those over qualified, just about 
$25 \%$ had tasks that are ICT (Information and Communication Technologies) related to carry out each week, compared to the $55 \%$ of the others who proved that those with a job that requires a university degree seems to do more job activities than those who are overqualified.

The study notes that, employees who are overqualified with higher capabilities could, in theory, acquire jobs that require higher skills and so represent a shortfall for the Canadian economy, with their potential underused. However, even though their situation can be explained by the labor market inefficiencies, there is also a chance that for them, it is a personal choice, with others preferring jobs that are less-stressful. Overall employees that are overqualified can be less satisfied with their job, about $13 \%$ of them, compared only to the $3 \%$ of workers who believes their degree, fits their job. When their dissatisfied, overqualified people tend to be less productive and or find another job that is in more in line with their degree and skill level.

The claims of Degallaix (2016) is supported by Mavromaras K. McGuinness S. and col, (2013). According to them overeducation and overkilling are distinct and worst phenomena. Their combination leads to the most severe effects and negative outcomes on the labor market. They analyze the relationship between both types of mismatch with pay, job satisfaction and job mobility using information on both educational and skill mismatch.

\section{Effects of Educational Mismatch}

Surprisingly, the previous claims made by the previous authors is somehow contradicted in the book Economics of Education Review by Bender and Roche (2013). The study dwells on the effects of educational mismatch but with a focus on wage and salary workers. In their study, they used a sample of employees in the field of science and engineering and the results show that the mismatched selfemployed individuals have larger earning penalties. But shockingly, the reason behind mismatch among self-employed individuals are dramatically affected by gender. Another research was done to extend the literature regarding educational 
mismatch by estimating the causes and effects of mismatch to self-employed individuals. In this time, they took sample of workers from the field of STEM or Science, Technology, Engineering and Mathematics who informed them the extent to which their job relates to their highest degree. The results show that compare to those wage and salary workers, self-employed workers have a higher chance of being educationally mismatched. The results indicate that self-employed workers earn larger penalties although there is no reduction in job satisfaction. Also, according to their data, they have found out that self-employed women have the most education, highest chance of being mismatched and largest earning penalty if mismatched.

This is also backed up and further explained by Jim Allen and Rolf Van Der Velden (2011) on his book Educational Mismatches versus Skill Mismatches: Effects on Wages, Job Satisfaction, and On-The-Job Search. They have stated that, labor supply and labor demand is usually evaluated by comparing the employees' acquired education, and it is being affected because of the educationjob mismatch. The expertise and skills of the employees are not optimally utilizing on the labor market, which reported to have serious effects on their job-satisfaction (Tsang and Levin, 1985), occupational choice (Viscusi, 1979), and labor turnover (Topel, 1986; Hersch, 1991). A major line of analysis has been developed relating to the result of education-job mismatch on wages. Overeducated employees tend to earn more than individuals who work in a job that level with their skills. In contrast, undereducated employees have higher wages than individuals with the same level of education for their required job, but less than individuals who has the appropriate attainment required for their job. The effects of wage of overeducation are usually stronger comparing to the effects of undereducation. From such perspective, the wage difference determined not in individual's productivity, but rather the agreement that is assigned to education and job categories. The productivity of the employees is determined if the level of education matches with the level of their jobs. The companies assigning the employees according to their skills, wherein the most suitable is assigned to the most complex job while the least suitable is assigned to the simplest job, and this affects their performances. 
Individuals working in a job that below one's own expertise will put their skills into waste. It affects the productivity of the workers, resulting in lower wages. This is also considered as undesirable, that the mismatch employees may be inefficient to their job. In addition, individuals who work above one's own level increases the productivity of the workers, allowing them to perform more than they would be when working in their own level. Study shows that, individuals' abilities are the reason of their productivity. Because from the very beginning, workers applying to a job are already performing at a level close to their own productivity not minding if the job they applied is not the same level to what their skills can provide.

On the other hand, the claims made by Allen and Velden (2001) are contradicted and opposed by Sattinger (1993). He stated that if an employee works in a non-compatible job, his or her skills are underused. This imposes a limit on the productivity of his labor, leading to lower wages. The apportion of workers is optimal if every worker matches a job in which he performs better than all other workers in relative terms. The transition from school to work is often seen as a' passage rite' in which young people are introduced to the working world. First, graduates must compete with those who have already taken a position on the labor market for the jobs available. Their lack of work experience often leads to unemployment. Secondly, a relatively large number of graduates end up in jobs which do not match very well to their educational skills. These job differences can be the result of incomplete information about the skills of graduates and the characteristics of employees ' jobs (OECD, 1998; Kerchhoff, 2000). Based on their hypothesis, the level of qualification determines the chance of being employed in an incompatible job. In a situation of over-education, the over-supply of highly educated graduates may result in "bumping down" as these better educated graduates begin to compete with less educated ones (Borghas and Grip, 2000). In consequence, better educated graduates find work in a rated field, but at a lower level of employment. However, this strategy is less useful for less educated graduates, as their opportunities to switch due to the smaller range of alternatives that exist for them. Therefore, they expect that the level of education achieved by graduates is negatively linked to the probability of being in a non- matching a job. 
In addition to education, different individual characteristics have an effect on the chance of getting employment mismatch. Gender variations on the labor market are found on an outsized range of dimensions. Generally speaking, woman have less favorable prospects on the labor market than men. (Blossfeld and Hakim, 1997).

There may be vertical mismatch when there is insufficiency at the level of skills, competences or education and horizontal mismatch when there is insufficiency due to the type of skills, competences or education that is different from the desired one. Education levels and skills have been shown to be strongly linked to the likelihood of employment and to salary levels (European Commission, 2016). Job mismatch is a complex phenomenon affecting the workforce, but the effects are different, such as productivity, wages, human capital, competitiveness and development. The mismatch is a situation of lack of balance or imbalances between the characteristics of employees, such as level or type of education, domain or co-competences that do not meet the requirements and responsibilities of the workplace.

In an article written by Maarten $\mathrm{H}$. J. Wolbers entitled, Job Mismatches and their Labour-Market Effects among School-Leavers in Europe, he supported the statement of Sattinger (1993). He investigated the factors of job mismatches with regard to the field of education among school-leavers in Europe. They have also examined the impact of job mismatches on the labor-market position of schoolleavers. Special attention is given to this problem to cross-national differences in this respect. The data used came from the EU LFS 2000 ad hoc molecule about school-to-work transitions. The empirical results show that the number of individuals, structural and work characteristics affect the chances of being job mismatched. Moreover, in countries which education system are vocationally centered, the incidence of job mismatches among school leavers is higher compared to countries with a mainly general education system. With respect to the labor-market effects of job mismatches, it was observed that school-leavers that mismatched to their job acquires a lower occupational status, more often looks for 
other jobs and participate in continuing vocational training, than those of job-fit individuals. These labor-market impacts of job mismatches are smaller in countries having vocational orientation in their education system is stronger.

Other authors have also agreed to the claims of Wolber (2003). According to Lourdes Badillo-Amador and Luis E. Vila (2013), in Spanish labor-market, education and skill mismatches are weakly related demonstrated by a statistical analysis. The key determinants of laborers' activity fulfillment are called skill mismatches, while having the much weaker impacts refers to the education mismatches, uncovered by the econometric analysis, just like on workers' job satisfaction; however, education and skill mismatches both obtain negative impacts on wages. Invalid interpretations of facts are the outcome of inadequate job-worker pairing fallout by ignoring the effects of education mismatch along with the skill mismatch in the examination of the non-monetary and monetary consequences Badillo-Amador and Vila (2013). Adding one more year of overeducation will increase the work income, however just half as solid as one more year of required tutoring. The evaluated consequences for long periods of undereducation are negative, however, undereducated specialists acquire more than sufficiently coordinated laborers with a similar dimension of instruction. In spite of the fact, specifically the rate of undereducation in Brazil, is a lot higher than revealed for created nations, the effect of over and undereducation does not vary. (Reis, 2017) The observational examinations gives three outcomes: first, no less than two-third of the measurably characterized overeducated laborers see their abilities as capable for the work they hold and are then obviously overeducated; second, overeducated laborers whose abilities are not suitable with their work do not get any reward to long stretches of surplus training; and third, clearly overeducated laborers have comparative wage returns contrasted with others with a similar tutoring level yet who are factually coordinated. With everything considered, these discoveries affirm that the vast majority of those overeducated as per the factual measure have imperceptibly abilities that enable them to work in an occupation for which they are very much coordinated. In estimating the educational mismatch in the labor market, horizontal and vertical skill mismatch 
must be considered. In that way, it is conceivable to represent laborer heterogeneity in abilities whose exclusion may create one-sided assessments of the occurrence and wage impacts of over-and undereducation. (Pecoraro, 2016) Among the organization's workforce, they disabled the productivity of the undereducated workers, suggesting that an organization's HR management should refuse to hire undereducated employees or workers, otherwise they will obey the short-term momentary staff rules and regulations. The impact for overeducated workers is likewise negative, though little and inconsequential (Grunau, 2016). The outcomes demonstrate that in Iran's labor market, the overeducated employees appreciate a wage premium in the scope of 10-25 percent for their abundance training when they need to work in semi-or lowexpertise occupations. While this relative preferred standpoint has slowly declined for private division workers over the period 2001-2013, it has stayed stable for open segment occupations. The outcome is closely associated to the fact that payment and advantages for open area representatives are specifically connected to education attainment and their work involvement. The discoveries demonstrate that the relative wage favorable position of overeducation is bigger for the more youthful representatives with ten or less long stretches of experience who have more knowledge than the older employees. To sum up, these discoveries offer a clarification for the powerful urge of Iranian youth for university education. If a college graduate finds an occupation that suitable for his/her specialization, he/she will appreciate a higher pay than a secondary school graduate. In the event that she/he needs to acknowledge a semi-skilled or low-skilled work for which he/she is overeducated, she/he still appreciates a wage premium over her/his colleagues who are not overeducated.

An equally important statement that agrees with Badillo-Amador and Vila (2013) is written by Quintano, Castellano and D'Agostino (2008), in an article entitled Graduates in Economics and Educational Mismatch: the case study of the University of Naples 'Parthenope'. The nature of occupations of financial matters graduates was examined as far as instructive crisscross. The profits of overeducation on income and on the job-search were additionally examined. The 
exchange respects the second flood of a longitudinal study of an irregular example of financial matters moves on from the University of Naples 'Parthenope', a noteworthy school of financial aspects in southern Italy. Overeducation was estimated utilizing two unique markers of instructive confound, one dependent on a target parameter and the other on a similar parameter joined with an abstract one. A profit relapse with choice was completed to dissect the impact of a lot of control factors, (for example, family, foundation, business topography and qualities of employment, work history, sex and channels used to enter the work showcase) on overeducation. Similar factors were utilized to ponder the profits of overeducation on income and on the job-search. The likelihood of being over-educated was fundamentally influenced by sexual orientation, achievements in Higher Education (HE), channels used to enter the work advertise, work area and employment division connected for. Females, bring down HE achievers and graduates working in exchange/deals or data frameworks areas were bound to be overeducated than different subjects, while utilization of further instruction to enter the work advertise diminished the likelihood of being overeducated. Overeducated specialists were found to have a high likelihood of low income. Overeducation and low profit prompted laborers to change employments.

Rong Zhu (2014) written a paper entitled, The impact of major-job mismatch on college graduates' early career earnings: evidence from China, that supports the claims of Quintano, et al., (2008). It surveys the effect of the bungle between a school major and employment on school graduates' initial vocation income utilizing an example from China. All things considered, a major- work jumbled college alumni is found to experience the ill effects of a pay misfortune that is much lower than the punishment recorded in past examinations. The pay misfortunes are additionally observed to be heterogeneous and around $33 \%$ of the confounded school graduates gain more than those coordinated ones.

On the contrary, an article written by Giorgio Di Pietro and Peter Urwin (2006) entitled Education and skills mismatch in the Italian graduate labor market suggests a solution that contradicts to the claims of the previous authors regarding the wage and profits of overeducated individuals. It centers around instruction and 
aptitudes bungle among Italian alumni. Pointers for over-and under-usage of instruction and under-use of abilities are incorporated as informative factors in a wage condition, testing speculations that could clarify the impact of over-tutoring on wages. We discover little proof to help task hypothesis and furthermore distinguish a moderately powerless wage impact emerging from instructive bungle related with managers', instead of representatives', impression of the activity prerequisites. Our translation is that a few businesses have re-arranged employments as requiring a degree, when they were recently filed by nongraduates, and many have not changed pay scales as needs be.

However, according to Barro and Lee (2001); OECD (2014), The existence of those mismatches raises queries on their effects on individual outcomes in the market like the work satisfaction. From the social science perspective, education job mismatches adversely have an effect on job satisfaction as a result of the worker's expectations on the social position and sort of labor are not consummated like they thought after they endowed in their education (Capsada-Munsech, 2017) Indeed, there exist empirical evidences on the negative impacts of over education on job satisfaction, which may cut back the workers' productivity. First, there's no accord on condition that some researches such as (Badillo-Amador \& Luis Villa, 2008), inexperienced \& (Zhu, 2010), (Sloane, 2014) do not realize any impacts. Indeed, some staff could like that kind of job in compensation for alternative job attributes such as less job pressure that they'll have stronger preferences (McGuinness \& Sloane, 2011). Second, less researches analyze the case of horizontal mismatches even supposing their effects seem to be reminiscent of the vertical kind (Domadenik, Farcnik \& Pastore, 2013). As an example, (B'eduw'e \& Giret, 2011) realized that horizontal pair decreases the work satisfaction among French business graduates and also the result are stronger if graduates also are overeducated. Third, most of studies appear to ignore the choice bias drawback as a result of the non-employed graduate's sample that would be mismatched if they selected to figure (Caroleo \& Pastore, 2013). Fourth, less researches target developing countries wherever mismatches appear to be higher (McGuinness, Flek \& Kurikova, 2017). As an example, we tend to solely realize (Zakariya \& Battu, 
2013) World Health Organization examine the impacts of overeducation on job satisfaction among graduates in Asian country and report negative impacts. The objective of this text is consequently to research if the vertical and horizontal mismatches decrease the work satisfaction among Cambodian university graduates by additionally considering the doable choice bias drawback. Thus, this analysis contributes to the literature on 3 main points: First, we have a tendency to examine the consequences of education-job mismatches from their each forms (vertical and horizontal) and additionally the mix of those 2 forms (a double mismatch) in an exceedingly developing country, specifically Asian country, that has simply captive from a coffee financial gain to a lower middle financial gain status in 2016, whereas alternative previous researches focus totally on over education and a lot of advanced economies. Asian country represents so a stimulating noteworthy\} case to contemplate given its remarkable rise in the enrollment rate in education what is more, around five hundredth of scholars square measure listed in social science, management and law majors, whereas Asian country is lacking of graduates in engineering (Madhur, 2014).Second, besides the everyday variables controlled within the previous literature, we are going to additionally control the match between the graduates' analysis on the importance and also the real implications of many job attributes in their current occupations like job autonomy, job stability, job salary, job challenge, career opportunities, probabilities to find out new things, reconciliation between working and family time, social rank, job leisure and doing helpful things for society. Being able to control these variables which will have robust impacts on the general job satisfaction ought to make our results a lot of strong. Consequently, we are going to use the Heckman probity model to cope with this issue, applied on a survey knowledge supported by the communicative University Agency, called AUF, and conducted by the French cooperation at the Royal University of Law and social science among nineteen education establishments in Asian country in 2011.

Also, in an article written by Brikend Aziri (2011), entitled Job Satisfaction: A Literature Review, he supported the argument of Barro and Lee (2001); OECD (2014). He defined Job Satisfaction as one of the complex areas that the managers 
are facing for them to manage their employees. Job Satisfaction has a dramatically large impact to the motivation of employees, and the level of motivation of an employee has an impact to the productivity and performance of business organization. Unfortunately, he stated there that in their region, job satisfaction still has not received proper attention from neither scholars nor managers of different business organization. Meaning, the problem has not yet resolved or even taken into consideration.

The same goes with Kampelmann and FrançoisRycx (2012). In their book The Impact of Educational Mismatch on firm productivity: Evidence from linked panel data by they gave a proof with respect to the immediate effect of instructive confuse on firm efficiency. To do as such, they depend on agent connected employer, representative board information for Belgium covering the period 19992006. Controlling for concurrence issues, time-invariant imperceptibly work environment qualities, partner impacts and elements in the change procedure of profitability, they find that (i) a large amount of required training applies on altogether positive effects on firm profitability, (ii) extra-long stretches of overinstruction (both among youthful and more established specialist) are useful for firm efficiency, and (iii)extra-long periods of under-instruction (among youthful laborers) are hindering for firm profitability. (FrancoisRycx, 2012).

Instructive jumble (or basically finished and under-training) alludes to the distinction between the specialist's achieved dimension of training and the instruction required in the activity. This critical wonder, first featured by Freeman (1976), has been broadly considered, particularly since the late 1980 s, so as to assess the results of the proceeded extension of cooperation rates in advanced education that are seen in created economies (McGuiness, 2006). For a long time, propelled economies have actualized arrangements intending to expand the dimension of instruction of their work drive. The European key system on instruction and preparing for example, expects to raise the offer of individuals, matured somewhere in the rage of 30 and 34 with tertiary training to 40 percent by a large in the European Union by 2020. This system verifiably accepts that there 
is an abundance interest for tertiary instruction or that organizations utilizing progressively taught specialists will enhance their creation strategies to take preferred standpoint of those extra abilities (McGuiness, 2006). In any case if these suspicions are not fulfilled then tertiary instruction may finish up in occupations for which they are finished instructed. Besides, in times of abundance work supply, there might be some 'swarming out', for example a procedure by which specialists with tertiary training take up occupations that could be involved by less instructed ones. The extent of over-instructed specialists in the OECD territory stands today at around 25 percent and around 1 out of 5 laborers is recorded as under-instructed (OECD, 2011). Given the size of this figures, "numerous onlookers point to: (i) the disappointment of the training framework in giving youth the abilities required at work, and (ii) the failure of work markets to sort numerous specialists to reasonable employments" (OECD, 2011, p. 193). Besides, McGuiness (2006) accentuates that instinctive bungle might be expensive for the economy in general (for example a waste in expense incomes because of the financing of exorbitant dimensions of instruction), for firms (for example a misfortune in proficiency if over -taught laborers may win not exactly their previous cohorts doing tasks that coordinate their training). From the existing explorations, the rate and income impact of instructive jumble are very much archived in the monetary writing and discoveries are very steady (Hartog, 2000; Leuven and Oosterbeek, 2011). In guaranteed work with a particular dimension of required training, over/under-instructed laborers procure more/less than the individuals who have quite recently the required training for the activity (Battu et al.,1999; Dalton and Vignoles, 2000; Frenette, 2004; McGiuness, 2003; Van Der Meer, 2006).

These are several studies that just proves Educational Mismatch as a very serious phenomenon. Books and articles are written and published by various authors to inform their audience about this occurrence and its effects. However, this problem undeniably does not get the attention that it needs. That is why, the researchers' chose this study. 


\section{METHODOLOGY}

\section{Research Design}

This study is a qualitative study that uses the phenomenological approach to collect data. Phenomenological approach concerns the understanding and interpretation of the meaning of everyday life of participants (De Vos, 1988). The qualitative approach focuses on the qualities of human behavior (Ferreira et. al., 1988). The aim of this method is not to generalize but to understand and interpret the meanings and intentions of all human actions (Bailey, 1997; Bogdan and Taylor, 1975; De Vos 1988; Ferreira et. Al., 1988).

Qualitative design deals with data that are primarily verbal and derives meaning from the perspective of the participant and also aims to understand the meaning of everyday life (Bless \& Higson Son, 1995; De Vos, 1998). The qualitative approach is appropriate for this study since the data collected and used focuses on the subjective experiences of the participant in the discourse process and their interpretation. It further explains that the qualitative research approach is unique in its ability to uncover the unexpected and explore new ways.

\section{Sampling Method}

Sampling, which is a non-probability sampling method, was used to develop a sample of participants who provided the study with the needed information. Purposive is a method by which the researchers will not be choosing a sample based on a level or an area but for a specific purpose (Arikunto, 2010: 138). The researchers have adequate information and suitable for the study. The researchers attempted to compile a sample of people from various backgrounds to obtain more varied data.

\section{Participants}

The researchers approached and invited them to participate in this study after prospective participants was identified. The information sheet was shown to the 
participants and they were informed of their right to decline participation and that the participation was voluntary. When the participants agreed to participate, the researchers also made them aware of their right to withdraw from participating in the interview. The researchers also informed that the information they have provided during the interview would also be treated confidentially and the participants were not required to disclose their identification details. The consent forms for their participation and for the use of the audio tape recording that they signed to give their consent was presented to them.

The participant consists of two (2) female and one (1) male Filipino graduates of Business Administration between the ages of twenty-five (25) to fifty (50). No participant has disclosed her identity. Full disclosure is a type of disclosure that involves revealing one's identity to everyone around the person. Whereas in full closure, involves not revealing one's identity fully to everyone around the person.

\section{Research Instrument}

The researchers formulated the research questions well, for this phenomenological study. The questions will be first examined and validated by Mr. Joseph Dave Pregoner, the validator. After the validation, the questions will be pilot tested. The instrument used in this qualitative phenomenological study are interview questions, and it was recorded for the purpose of authenticity. The questions were written and asked in English, and the participants can use the language they like to express themselves freely without uncertainty.

\section{Data Collection Method}

The collection of data for this research was done through face-to-face interview with each participant having his/her own schedule. Ferreira et al. (1985) stated that, among all the data collection instruments, the most important one is interviewing. The researchers will be implementing interviews with semi-structured questions. It is to give follow up questions with regards to the answer of the respondent that might not have been included in the set of questions prepared, but may also contribute necessary details for the success of this study. The researcher 
may be able to ask for clarification if something was not clear or to ask the participant to expound his/her ideas and thoughts towards a particular issue. Through face-to-face interview, the researchers will be able to read the gestures, body language or more generally the non-verbal communication exhibited by the participant. The interview sessions will be audio recorded and will be transcripted by the researchers later on.

According to Bogdan and Taylor (1975), a part of the basic principles of unstructured interviewing were acceptance and understanding. It is a very important variable in building rapport between the researcher and the participant as the participant sees the researcher non-judgmental towards them. The researchers also are doing their best to be cautious enough of the involvement of emotions both of the researchers and the participants as it might impact the reliability and validity of the results (Ferreira, et. al., 1988). Bogdan and Taylor (1975) also stated that, making the participants feel comfortable and give his/her thoughts freely without any doubts is the responsibility that needs to be fulfilled by the researchers by setting the atmosphere the best for the participant. It can be achieved by letting the participant choose the place where the interview will be conducted.

\section{Data Analysis Method}

Thematic content analysis will be implemented by the researchers to analyze the results from the data gathered. Ezzy (2000) described it as a way to analyze data by classifying it into different categories depending on the themes, concepts, and or similar features. The purpose of the researchers in employing this kind of content analysis is to transform data in a more concise manner, while putting them into categories as meaningful units for interpretation (Singleton, 1997). Marshall and Rossman (1989) in De Vos (1998) had introduced the steps to develop the themes that include the following procedures: 


\section{Organizing data}

The data gathered by the researchers will be repetitively read for them to be familiar with the data.

\section{Generating categories, themes, and patterns}

In this stage, creative and analytical thinking is needed. The researcher will be identifying the things that assisted the integration of results such as the most important themes, recurring ideas, and patterns of belief. Together with the rise of different categories of meaning, the ones who are internally consistent but is distinct from each other are searched by the researchers. This has resulted on the uncovering of the patterns, themes, and categories.

\section{Testing emergent hypothesis:}

When division and the patterns are evident in the data, the researchers then assess the credibility of the evolving hypothesis, and then test them against the data. The process will involve the evaluation of the data for their informational sufficiency, credibility, serviceable, and centrality.

\section{Searching for alternative explanation:}

As the division and patterns between them arises, the researchers engaged in the challenging of the patterns that reputed the act. An option explanation was casted, and described them until the researchers find the right reasons for the study.

\section{Trustworthiness of the study}

As this qualitative phenomenological study was conducted, the researchers offered letters to the three (3) participants. The letters were about the agreement wherein the information that was gathered will be treated with utmost confidentiality. In order for the research to demonstrate trustworthiness, the research should have transferability, dependability, credibility, and conformability. In terms of validity, the researchers assured that this research is for the researchers to be able to distinguish the correct operational measures for the notion that was studied (Pandey and Patnaik, 2014). In this case, the researchers 
used interviewing because it is useful in gathering in-depth information from the participants about the topic. (McNamara, 1999).

The researchers were confident regarding the credibility of the results since all participants are certified to have an associate's degree in business. In interviewing the participants, the ethical consideration is already regarded by the researchers. The participants can convey themselves without any interruptions from the researchers. Lincoln and Guba (1985), asserted that it is the researchers' duty to provide enough information about the topic to the participants to provide transferability. To show transferability, the researchers will be providing thick description; a term coined by Geertz (1973) which implies that the research should not only have factual information but also have commentaries and interpretations. The researchers will supply specific information, that relates on-filed experiences. To prove dependability according to Lincoln and Guba (1985), a researcher should engage inquiry audit. In this research, the researchers will have another researcher from the outside to observe the process and product of the research study (Lincoln and Guba, 1985). This outside researcher will portray the full details how the data was gathered throughout the research, how the categories are obtained, and how the decisions were made in the research. The reason for this is to know how accurate the data and to evaluate whether the findings, conclusions, and interpretations were supported by the collected data. To show conformability, the researchers make sure that any biases are not permitted and done throughout the whole research. The researchers ask questions with utmost respect. The researchers checked and assured that all information that were gathered will not be fabricated and falsified. After transcribing their responses, the participants will then double check the papers and will then be asked by the researchers to sign at the lower right portion to make the written work factual as a sign of authenticity. Lastly, researchers will then make sure that the respondent's identity will be confidential. 


\section{Ethical consideration}

After the participants were informed to participate, they were first given the informed consent. This was attained by informing the participants about the informed consent and the recording tapes that will be used during the interview and ask them to sign, to know their approval. Participants are already informed about the confidentiality clause. Confidentiality indicates that the dignity of the participants will be respected. Therefore, it is important that participants will know that any information will be regarded as confidential (Ferreira et al., 1988). Participants were informed that their confidential information will be accessed by the researchers and the supervisor. The participants will be asked for their personal information such as name but after transcribing, the tapes that are keep safe in a confidential place, after the study will be finished the tapes would be destroyed.

\section{Role of the researchers}

The researchers play a vital role in this study for they are the one who will act and find a solution to the problem of the study. The researchers engaged in the gathering of data such as conducting interviews to have an in-depth, and factual information about the experiences and stories of the participants about the topic. Furthermore, the researchers will be providing thick descriptions about the context and facts in the study. They will be the one to make questions that are related to the study, will be the one to record and transcribe the answer of the participants and then find the central theme of the phenomenology study. 


\section{RESULTS AND DISCUSSION}

This chapter is centered on presenting and analyzing the empirical research findings with the main focus on the research questions of the study. The research question was:

1. How does UIC graduates in the field of business administration face the problem of education-job mismatch?

To answer the above questions and meet the research objectives, the study employed the in-depth interview technique conducted with UIC graduates as the main primary data collection technique. The chapter is divided into two main sections. The first section presents the issue of education-job mismatch from the perspectives of the graduates. It pays attention to graduates' own understanding and definition of the concept of education-job mismatch, graduates' experiences of education-job mismatch and the perceived causes. The second section deals with the impacts of education-job mismatch on the graduates.

A summary and outline of the themes are shown in Table 1. As shown in the table, there were three parts of information used to generate data on the first research question. These were the graduates' perspectives of education-job mismatch, job search and market experiences, and perceived causes. A total of nine themes were formulated based on these categories. Three themes were created in the second research question. 
Table 1. Summary of themes

Categories Themes

\section{Education-job mismatch among}

University graduates

Graduates perspectives Horizontal and vertical

Job Search and Labor Market Not useful qualifications

Experiences

Career alienation

Career goals and aspirations were

not realized

Perceived causes

Theory and practice misalignment

Field of study

Weak economy and inadequate job

opportunities

Excess supply of graduates

Outdated curriculum and absence of course relevance

Impact of education-job mismatch on Income graduates

Job satisfaction

Human capital depreciation

\subsection{Education-job mismatch among university graduates}

Graduates' Perspectives

During the interview process, the participants were asked to describe their own understanding and definition of the concept of education-job mismatch. The following are some of the responses gathered:

Participant A had this to say: 
"...let me start with the word mismatch itself. To me mismatch means when things do not complement or do not relate. In the context of this subject this means a lack of relationship between education and job. If I may give an example someone who has a degree in English Language and ends up as a street vendor or businessman can be considered mismatched. In another way I can say if you have a degree and you do a job that requires a secondary school certificate or lesser qualification, this can also be considered a mismatch."

Participant $B$ held this in view:

"In my opinion education-job mismatch is when there is no link between what you studied and what you do for a living. For example, you are a History teacher and after you graduated, you end up working as a security guard."

When Participant $C$ was asked to describe her understanding and definition of the term education-job mismatch, she took a deep breath and stated:

"I can say mismatch involves not being able to work in your domain. That is, circumstances might have caused you to deviate from your area of study and you now do something else not related to what you studied. For instance, if you are a geography graduate but you end up working as a clerk."

The participants understood education-job mismatch from diverse points of view. Without necessary using conventional and classical terms like vertical and horizontal mismatch used in the literature, they described their understanding of education-job mismatch and used examples which could be categorized under these two types of mismatches. For example, Participant's B example of being a History graduate and working as a security guard and Participant's $C$ example of being a Geography graduate working as a clerical clerk implies that they are both vertically and horizontally mismatched. They are vertically mismatched in the sense that a degree was not a requirement to secure a job as a security guard or as a clerical clerk and horizontally mismatched in the sense that they do not apply the knowledge acquired through school in their present jobs. These views are consistent with what has been reported in the literature, that education-job mismatch occurs when the qualification of an employee does not match the 
qualification of the job, he/she does (Mahuteau et al., 2014) or when a worker trained in a particular field of study works in another field (Montt, 2015).

The participants showed a great understanding of the term education-job mismatch and without being labelled directly as mismatched graduates by the researcher most of them used themselves to substantiate their definition of the term and acknowledged that they were facing a mismatch. A summary of all the research participants, their field of study, the jobs they held at the time of the interview and the type of mismatch is presented in table 2 below.

Table 2. A summary of research participants, their field of study and the jobs they held during the interview period

\begin{tabular}{|l|l|l|l|}
\hline Participants & Field of study & $\begin{array}{l}\text { Job held during the } \\
\text { interview period }\end{array}$ & Type of mismatch \\
\hline A & $\begin{array}{l}\text { Business } \\
\text { administration }\end{array}$ & Call center agent & Vh \\
\hline B & $\begin{array}{l}\text { Business } \\
\text { administration }\end{array}$ & Waiter & Vh \\
\hline C & $\begin{array}{l}\text { Business } \\
\text { administration }\end{array}$ & Seamstress & Vh \\
\hline
\end{tabular}

Legend: v - vertical, $\mathrm{h}$ - horizontal

Job Search and Labor Market Experiences of Graduates

The absence of unemployment insurance forces individuals that do not have resources to withstand prolonged unemployment either to create their own jobs or to accept jobs whose skills match, social security, remuneration, job security and other features are inferior to jobs they expected to have. This menace of unemployment has pushed many graduates especially those in the field of business administration to engage in jobs which require little or no knowledge acquired during their degree programs. These graduates after spending their limited resources and several years in the university to obtain a degree often end up with jobs which a degree is not required or knowledge acquired is not applicable. 
During the interview process participants were asked to describe their job search journey after graduation up to where they were during the period of the research. Each participant had their own story to tell about their experiences and the road they had travelled up to where they were at the time of the interview. Their experiences ranged from the difficulties in finding a job, the type of job they secured, how they got the job and the relationship between their job and their education.

Participant A narrated her story:

"After graduation, it took months for me to find jobs. I had given my application letters to different employers ... after so many rejections, I decided to apply for jobs that were not aligned with my degree. Luckily, I got accepted but the idea saddens me ... this is not what I planned."

Recounting her job search experience, Participant B said:

"At that time, there were so many of us [graduates] ... the competition was very great. I had to be the best ... but even if you are the best if no one will get you, you are nothing. Why settle to business firms if there are other offices."

Participant $\mathrm{C}$ also mentioned:

"My first job was very different from my degree. I felt the degree I get from college was not useful."

The research participants who shared the above job search and labor market experiences represent just a fraction of the thousands of university graduates in the Philippines who roam the street searching for unavailable jobs. These graduates, resort to non-graduate jobs as a way to escape joblessness and to make ends meet. The research participants felt their qualifications were not useful in helping them to secure a graduate job. They felt their academic achievements made no difference because despite the fact that they were degree holders they ended up in jobs that a degree was not a prerequisite and they shared common jobs with nongraduates. Career alienation was evident from their stories and there was a feeling that the work they held at the time of the interview did not contribute to the realization of their career goals and aspirations. What they did for a living looks nothing like the dreams they had. 


\section{Perceived Causes of Education-Job Mismatch}

As elaborated in the previous section, the graduates after spending costly years to obtain a degree found it difficult to secure graduate jobs and were forced to engage in jobs which neither a degree nor the knowledge acquired was required to do the job. The reasons for this mismatched are many and varied. The participants framed the perceived causes of education-job mismatch around both individual and structural level factors. The individual level causes had to do with lack of practical skills and work experience, and constraints brought about by the field study while the structural causes included: the declining public sector and the stagnating private sector, the overall weak economy which has made job creation difficult, outdated curriculum, the absence of course relevance, and excess supply of graduates.

Theory and Practical Misalignment. The participants were concerned with the type of knowledge they receive from the universities and acknowledged the fact that they had insufficient practical training while they were in school. Most of the participants perceived the university system as inadequately designed to the actual changing needs of the labor market and reported that the curricula are overly theoretical, leaving graduates feeling ill-prepared and lacking necessary practical skills for the job market. To them this was one of the reasons why they could not find jobs in their field of study. They supported their arguments with the type of skills demanded by employers when they advertise a job opening and the type of questions, they were being asked during job interviews (for those that had the opportunity to attend a job interview).

Participant $A$ held this view:

"I had jobs before the present ... they [employers] assigned me to different office ... I just do not know why. I only remembered that one of my supervisors told me I cannot do my job well on that office. I was not taught how to do it when I was in college ... but I really did my best to learn during my stay at that job position."

On a similar note, Participant $B$ recounted: 
"Honestly, there was a big gap between the theories taught in school and in actual practice ... what awed me was that why did my co-workers know how to do this and that. They [co-workers] graduated from different school."

A degree is evident that the graduates have academic qualification but employers want to see that these graduates can apply this academic knowledge physically in the work place. University teaching is theory based, as what the participants said, there are no internship opportunities for graduates and the universities do not offer any labor market options or career services. Therefore, gaining access to work experience demanded by employers is a difficult and challenging task for most graduates as they are caught in a vicious circle where they cannot get a job without work experience, yet they cannot get work experience without a job.

The Field of Study. The field of study was also mentioned by the participants as one of the factors that influenced their employment outcomes. The choice of a degree program has a crucial role to play in a graduate's employment prospects. Some of the participants acknowledged that their field of study was actually a barrier to their career success. They choose what interest them or what they are good at without considering what it can actually do for them and they do not feel the impact of the current labor market until after graduation. Some participants felt their fields of study were over-subscribed and there was low market demand for their skills.

Participant $\mathrm{C}$ remarked:

"I had to choose the course because I like business. I can see how successful are the businessmen in the community. After graduation, I realized that there is a low market demand for this field."

Participant B mentioned:

"... influence of others was one of the reasons of taking the course. However, during my stay at the university, I was disappointed ... I foresee the future ... unemployment, difficulty in finding the right job among others. I do not see the community badly needs us." 
As it is evident in the above quotes, peer pressure, the influence of siblings and personal interest motivated the participants to pursue certain fields of study without thinking of what the future holds for them. They studied just to realize upon graduation that the future is bleak because the market for these fields is saturated and the demand is low. Graduates face great employment challenges because of their chosen field of study. This supports Migdad (2011) view that the choices of field of study by students may not be based on any prior plan or link to the labor market but rather on personal ambitions and desires. The British Council on (2015) noted that the field of study is affected by demand side factors; these are not 'natural' but shaped by a discourse of 'scarce skills' and this especially affects the humanities and social sciences whereas accounting, business and commerce students and engineering students perceive positive employment prospects due to the demand for graduates with their qualifications. The African Development Bank (2012) also found out that Africa has the highest share of social science and humanities graduates than any world region. The Philippines is not an exception in this case as thousands of humanities graduates are churned out every year and these graduates find it difficult to secure career jobs.

Weak economy and inadequate job opportunities. The university can impart graduates with the right skills yet the problem of graduate unemployment and subsequent job-mismatch will still persist if career-oriented jobs are not available for the graduates. The absorption of the growing numbers of graduates depends not only on the subjects studied or the possession of skills and academic qualifications, but also on the ability of the public and private sectors to create jobs (Migdad 2011). In the postcolonial period, higher education in Asian countries was largely to select a few to enter high-ranking government jobs. With the expansion of university systems, diversification of economy and a drop-in public-sector job opportunity, the labor market today cannot be counted on to absorb university graduates as was the case in the 1960s up to early 1980s. The unprecedented economic crises that the Philippines suffered in the 1990s is one of the root causes of graduate unemployment as the government had to retrench many workers within the public service to sustain the overall debt burden of the country (Geo- 
Jaja \& Mangum, 2001). Since then, the situation of youth unemployment in general and graduate unemployment in particular is constantly on the upsurge (CAMYOSFOP, 2014). The government has not been able to create adequate job opportunities, leaving thousands of graduates waiting for years to fill vacant positions in the public sector.

Participant A urged:

"If you can observe ... most of us [business administration graduates] are not in the business field. I found the job opportunities not fair to us ... it takes a lot of time for us to find the right fit ... that is why we resort to jobs that are not related in our field. This is really a call to government."

Excess supply of graduate. Excess supply of graduates in the labor market was also consistently cited by the participants as one of the reasons behind education-job mismatch among university graduates. Participants were of the opinion that there is excess supply of graduates over demand and this makes it difficult for many graduates to find career-oriented jobs especially in the saturated labor market.

Participant B remarked:

"We are the largest [number of graduates] at our time ... it's 1 vs $1000 \ldots$ I mean, for every 1000 of the business administration graduates, the community only needs 1 , that is what I think. There is an imbalance."

Outdated curriculum and absence of course relevance. The participants were also concerned about the relevance of the curriculum used and the type of courses offered in the universities. They were of the opinion that the university is largely out of synchronization with the society. The education is wishy-washy and not tied to the needs of the labor market. Some aspects of the syllabuses are outdated and are focused on imparting knowledge that does not meet the national needs and woefully out of step with the labor market trends.

Participant $\mathrm{C}$ remarked:

"I believed there were some parts of the curriculum that are not applicable to the present days ... teachings in the school must continually change and adapt, just like technology." 
The next section presents findings which inform the second objective of this study: to find out how not being able to secure a career-oriented job and working in a non-graduate job has affected their lives.

\subsection{The impacts of education-job mismatch on the graduates}

\section{Perceived Income Effects}

Education is often viewed as an investment and as the main tool to fight poverty as it is assumed to help individuals find better jobs, thereby increasing their earnings in the labor market. The returns to higher education as assumed by the human capital theory manifest themselves in higher individual earnings and better career progress opportunities (Beck 1993). While the importance of education is emphasized as inherently related to the development and well-being of people, its economic efficiency is more debated (Kuepié and Nordman 2015). Such a direct and linear relationship between higher education qualification and economic returns is not fully reflected in the Philippine labor market as an increasing number of its graduates are found colonizing non-graduate positions in the labor market. Such positions are characterized by poor earnings, poor career progression opportunities as well as limited labor market scope.

Unsurprisingly, the findings of the study revealed that, the participants perceived their earnings to be negatively related to education job-mismatch. The participants reported low and irregular remunerations. While some participants reported they earn low wages, others were more concern about the irregularities of their income and at the same time some recounted worries about both the amount and irregularities of their income. However, few of the participants were very content with their income and reported other worries of job mismatch rather than income. Though data for their matched counterparts was not collected to compare whether or not income effect was due to mismatch, such a comparison was beyond the scope of this study. However, the type of jobs the participants secured (non-graduate jobs) and the stories recounted by participants revealed that they suffered negative income effects as a result of being mismatched. First the participants were employed in non-graduate jobs, that is, in jobs which do not 
take into account their level of education and field of study. This therefore implies that their status of being a graduate was not considered when income arrangements were made. Payments were made based on the job characteristics and the assigned tasks and since these were mainly non-graduate jobs their qualification made no difference. They could not use their certificates to bargain on the salary or to demand for salary increment.

Participant $B$ recounted:

"I do not know what should I feel ... aside from working in a totally different language [of field], I cannot really say that I am happy with the salary I get ... receiving money from something you do not like ... not worth the sweat."

\section{Job Satisfaction}

Apart from the income effects, participants also associated education jobmismatch with low job satisfaction. Job satisfaction as Locke (1976), defines it refers to a positive or pleasant emotional state resulting from a person's appreciation of his/her own job or experience. It involves a sum of the utility derived from all aspects of the job (Hamermesh, 2001). This includes fringe benefits, the job content, and relationship with co-workers among others. Other things being equal, individuals select majors with the expectation of working in an occupation related to the chosen field of study (Robst, 2007). In this case individuals working in an occupation outside their field of study face the disappointment of unmet expectations and such individuals are less likely to be satisfied in their work (Montt, 2015).

The findings of this study revealed that even those participants who were contented with their income shared the view that, though the income is encouraging they were dissatisfied with their jobs. As elaborated in the first part of this chapter where the participants shared their job search and employment experiences, past unemployment spell and long search periods pushed many of the participants into undesirable and unattractive jobs which have left them dissatisfied with what they do. Their long search period, numerous experiences of unemployment and inability to secure a decent and career-oriented job compelled the participants to accept any job. 


\section{Human Capital Depreciation}

Human capital depreciation was another pathway through which education job-mismatch was perceived to have affected the lives of the participants. As Laureys (2012) suggested, workers' human capital erodes during periods of unemployment. Similar human capital erosion is thought to apply to mismatched workers since they are in jobs that do not make use of the knowledge they acquired through school. The participants of this study expressed worries about the knowledge and skills they acquired in school. They shared the views that their inability to work in their fields of study is resulting to loss of knowledge and skills they gained through school.

Participant A remarked:

"Of course, if you work in a field you did not study ... all of the learnings are like things that when not nurtured, will slowly degrade in terms of quality. Memorizing business terms in four years ... then doing different in another four years. If I will take an exam about business administration at this moment, I probably get zero [laugh] ... I totally deleted most of the topics. This is very disappointing."

As evident in the above quotes, education-job mismatch results to human capital depreciation or erosion because the jobs they secure do not correspond with the knowledge the mismatched employees acquired in school. They studied with the hope of securing employment in their domain of study and since they could not hold on to a job in their field of study, what they have acquired through school was wasting and even diminishing. 


\section{CONCLUSION AND RECOMMENDATION}

The aim of this study is to explore the different perspective of UIC graduates in the field of business administration regarding education-job mismatch. From the data presented, several themes have been made to interpret the data and make a conclusion out of it.

\section{CONCLUSION}

Results show that educationally mismatched individuals, felt that their qualifications were not enough to help them find a secure job because they can see no difference with non-graduates despite the fact that they are degree holders. It made them believe that it was not necessary to obtain a degree because applying for a certain job does not require it. This results to career alienation with them being alienated to the job they are currently in, and not being able to meet their career goals and aspirations when they were still studying. After spending several years investing their future at school, it seems that they are having a hard time to find jobs that is why, they are forced to seek for jobs either related or not related with their course.

Teachers also play a vital role in preparing their students for their future. However, it shows that the teachings misalign with the actual work that needs to be done for a specific job. Mismatched individuals undoubtedly accept that they had insufficient knowledge and skills while they are in school. Universities and Teaching institutions are often perceived as inadequately designed to fill the gaps between the needed skills and the student's learnings. It failed to respond in a fastchanging society which results not being able to meet the demands of the labor market, resulting to the irrelevance of the course itself. The researchers had raised possible solutions for this, either improved marketing strategies towards the course

and its opportunities and update the educational curriculum to respond to the needs and changes of the labor market and the society. 
The field of study of the mismatched individuals itself has something to do with the perceived causes of education-job mismatch. Mismatched individuals tend to have chosen a specific field of study because it interests them or it is what they are good at. They do not consider its possible labor market impacts, but only after graduation. They have felt an over subscription of their field of study and that their skills have low demand in the market. This resulted to their acknowledgement about their field of study being the barrier to their success itself.

The economy of the country is weak enough having inadequate job opportunities in the labor market. Universities can produce skilled and knowledgeable graduates every year but, it will just result to either unemployment or education-job mismatched. The availability of the public and private sectors also is one of the factors which affects the absorption of growing numbers of graduates. Fresh graduates will not be able to fill in a specific vacant job position because there is no vacant job position, or if there is one, it still cannot hire every graduate that a university has produced.

The dramatically large increase in the number of graduates makes an imbalance with how much the labor market only needs. This results to graduates having a hard time finding career-oriented jobs because of the excess supply of graduates.

Educationally mismatched workers, suffers either low and or irregular income. Mismatched workers earn less compared to job-fit workers. This is because employers perceived them to contribute less because their field of study, does not relate with the job they applied, compared to the others. But their employers might have just employed them despite the situation because there is already no one to fill in the position.

Working in a job not related to your field of study easily results to low job satisfaction. This is because mismatched workers may have been forced to work for a certain job that does not interest him/her. This will also lead to low work performance and later on, poor company/organization performance. He/she may 
only be one single individual but he/she is still included in the business' or company's operations and if detected, it will result most likely to work termination.

A mismatched worker will experience human capital depreciation which is caused by working in a different field compared to his/her field of study. While studying, a student is formed and is feed with learnings and skills that will help $\mathrm{him} / \mathrm{her}$ in the future. If your field of study does not match with your current job, those knowledge and skills you have acquired will slowly depreciate because you are working in an area you are not supposed to. You will be forced to transform the skills you originally had before having a job, to the skills your current job needs.

The researchers can conclude that, education-job mismatch have different effects and causes to people.

\section{RECOMMENDATION}

For the betterment of this research study, and the upcoming generations planning for its development, the following are recommended by the researchers:

- Use larger number of participants and do not settle for three, to have more varied data from more varied participants.

- Include individuals that are not educationally mismatched and unemployed graduates to be able to compare them with those who experienced education-job mismatch.

- Lessen the qualifications to be a participant. Use participants that may or may not be a graduate of business administration or of the University of the Immaculate Conception.

- Spend more time to be able to fully ensure the accuracy of the research. 


\section{REFERENCES}

Allen \& Velden (2001). Educational Mismatches versus Skill Mismatches: Effects on Wages, Job Satisfaction, and On-The-Job Search. Maastricht. Amsterdam: Oxford University Press.

Alipio, M. (2020). Predicting Academic Performance of College Freshmen in the Philippines using Psychological Variables and Expectancy-Value Beliefs to Outcomes-Based Education: A Path Analysis. https://doi.org/10.35542/osf.io/pra6z

Alipio, M. (2020). Academic Adjustment and Performance among Filipino Freshmen College Students in the Health Sciences: Does Senior High School Strand Matter?. https://doi.org/10.35542/osf.io/xq4pk

Arado, J. (2018, May 1). Over 1000 applicants flock to job fair. Sunstar Davao. Retrieved from https://www.sunstar.com.ph/article/1741144

Aziri (2011, December). Job Satisfaction: A Literature Review. Retrieved from https://www.researchgate.net/publication/222103547_Job_Satisfaction_A_ Literature_Review.

Bender, K.A. \& Roche, K. (2013). Economics of Education Review. North Menomonee River Pkwy. Milwaukee: Elsevier Ltd.

Betti et al., (2010). Educational Mismatch of Graduates: A Multidimensional and Fuzzy Indicator. Retrieved from https://www.researchgate.net/publication/226427045_Educational_Mismat ch_of_Graduates_A_Multidimesional_and_Fuzzy_Indicator

Chevalier \& Lindley (2009). Overeducation and the Skills of UK Graduates. Retrieved from https://www.researchgate.net/publication/227375647_Overeducation_and the_Skills_of_UK_Graduates/amp

Dalton \& Silles (2008). The effects of over-education on earnings in the graduate labour market, Vol. 27 (Issue 2). p. 126-139

Degallaix (2016, September 8). Over Qualification and Job Satisfaction: The Study. Retrieved from https://www.hrjob.ca/overqualification-and-jobsatisfaction-the-study/. 
Depasupil (2017). 1 Million Graduates face Job-Skill Mismatch. Retrieved from https://www.manilatimes.net/1-million-graduates-face-job-skillmismatch/317111/

Di Pietro \& Urwin (2006, August 20). Education and skills mismatch in the Italian graduate labour market. Retrieved from https://www.tandfonline.com/doi/abs/10.1080/00036840500215303.

Ghaffarzadegan et al., (2017, September 16). Work-Education Mismatch: An Endogenous Theory of Professionalization, Vol. 261(Issue 3). p. 10851097. Elsevier Ltd.

Kampelmann \& FrançoisRycx (2012, December). The Impact of Educational Mismatch on firm productivity: Evidence from linked panel data. Retrieved from

https://www.sciencedirect.com/science/article/abs/pii/S027277571200080 5 ?fbclid=IwAROLhEjsT9HtFwR4HqdoitHVu3qTsLPeMzVpLK8Xzp63uhTwmIPRKR7sts

Kim \& Choi (2018). The effects of Job Mismatch on Pay, Job Satisfaction, and Performance. Retrieved from https://www.researchgate.net/publication/328468153_The_Effects_of_Job _Mismatch_on_Pay_Job_Satisfaction_and_Performance

Kucel, A. (2011). The Sociology of Educational Mismatch. Barcelona. Spain: Polish Sociological Review.

Naimatul (2014). CHAPTER III RESEARCH METHODS. Retrieved from http://repo.iain-tulungagung.ac.id/489/4/CHAPTER\%20III.pdf

Ordine \& Rose (2017). Too Many Graduates? A Matching Theory of Educational Mismatch, Vol. 11(Issue 4). Retrieved from https://www.journals.uchicago.edu/doi/abs/10.1086/694455?journalCode=j hc

Prisca (2016). Education-Job Mismatch among university graduates in Cameroon. Retrieved from https://www.duo.uio.no/bitstream/handle/10852/54125/Ntemngweh-PriscaMaster-thesis.pdf?sequence $=5$ 
Pellizari \& Finchen (2017, January 13). A New Measure of Skills Mismatch: Theory and Evidence from PIAAC. Retrieved from https://izajole.springeropen.com/articles/10.1186/s40172-016-0051-y

Quintano, et al., (2008, April 1). Graduates in Economics and Educational Mismatch: the case study of the University of Naples 'Parthenope'. Retrieved from https://www.tandfonline.com/doi/abs/10.1080/13639080802214118?fbclid =IwAR03FfcgPe8rhxJSMelmrR6gNPXr4OAgC4FEGdQSTO30gvKNXHvl MhAUvOw.

Rahona-Lopez \& Perez-Esparrells (2013). Educational Attainment and Educational Mismatch in the First Employment in Spain. Madrid. Spain: ISRN Education.

Rong Zhu (2014, February 22). The impact of major-job mismatch on college graduates' early career earnings: evidence from China. Retrieved from https://www.tandfonline.com/doi/abs/10.1080/09645292.2012.659009.

Somers et al., (2016). Horizontal Mismatch between Employment and the Field of Education: Evidence from a Systematic Literature Review Maastricht. Amsterdam: Tier Working Paper Series.

Velciu (2017, December). Job Mismatch - Effects on Work Productivity. Retrieved from

https://ideas.repec.org/a/cmj/seapas/y2017i15p395398.html?fbclid=IwAR3 BIU8IdtPXNpsDEPNHr2WpYJm0gXoOJlbK7NKNyiMc-K1tGlwcu7y23z0.

Wolbers (2003, July 1). Job Mismatches and their Labour-Market Effects among School-Leavers in Europe. Retrieved from https://academic.oup.com/esr/articleabstract/19/3/249/469115?fbclid=IwAR0CDoUbdzzGVFTTLymqYsxo5oH Cy0-mJ6CsSf. 